\title{
DAMPAK MEDIASI MORAL REASONING PADA PENGARUH ORGANIZATIONAL ETHICAL CULTURE TERHADAP KECENDERUNGAN KECURANGAN AKUNTANSI
}

\author{
Hidayatul Khusnah, Heni Agustina \\ Prodi S1 Akuntansi Fakultas Ekonomi dan Bisnis Universitas Nahdlatul Ulama Surabaya \\ e-mail: hidayatul.khusnah@unusa.ac.id
}

\begin{abstract}
The purpose of this study is to investigate the mediating effect of moral reasoning on the influence of organizational ethical culture on the tendency of accounting fraud. This research was conducted at manufacturing companies listed in the guide book PT. SEER. The sample in this study is the financial manager or accounting manager. The number of samples in this study were 63 respondents. Total questionnaires distributed were 78 questionnaires, but as many as 65 questionnaires were returned, there were 2 questionnaires that were not filled out completely, so were excluded from testing. The hypothesis in this study was tested using Structural Equation Modeling (SEM) with an alternative method of Partial Least Square (PLS) using WarpPLS 5.0 software. The results of this study indicate that organizational ethical culture has a positive effect on moral reasoning and the tendency of accounting fraud. The next finding is moral reasoning has a positive effect on the tendency of accounting fraud.
\end{abstract}

Keywords: moral reasoning, organizational ethical culture, tendency of accounting fraud

\section{PENDAHULUAN}

Beberapa tahun terakhir ini, di Provinsi Jawa Timur kasus skandal keuangan semakin meningkat, baik pada sektor swasta ataupun sektor publik. Pada sektor publik, kasus skandal keuangan di Provinsi Jawa Timur terutama dengan pelaku pejabat daerah bisa dikatakan sangat tinggi (BPK.go.id). Kasus skandal keuangan di Jawa Timur sudah mencapai 81 kasus dan telah merugikan keuangan negara mencapai Rp4,16 M (Detik.com). Tjahjono (2013) mengatakan hanya sekitar seperempat dari kasus fraud terungkap karena internal audit, dan seperempatnya lagi terungkap oleh adanya proses internal control atau bahkan secara tidak sengaja.

Fraud dapat terjadi pada semua perusahaan, baik itu perusahaan kecil, menengah ataupun perusahaan besar. Pada dasarnya akar dari sebuah kecurangan adalah rendahnya etika indi- vidu masing-masing. Beberapa penelitian telah membuktikan bahwa kecurangan yang terjadi dipengaruhi oleh etika atau moral (Wilopo, 2006; Puspasari dan suwardi, 2013; Prawira et al., 2014; Eliza, 2015 dan Udayana dan sri, 2017). Seseorang dengan kemampuan penalaran moral tinggi akan lebih mampu memahami konsekuensi dari keputusan kebijakan, sehingga mereka lebih stabil dan konsisten dalam menanggapi keputusan kebijakan dan keputusan tindakan yang akan diambil. Manburg (2001) menemukan dalam penelitiannya bahwa terdapat korelasi negatif namun tidak signifikan antara sikap yang kuat dan kemampuan penalaran moral yang baik, artinya bahwa kemampuan penalaran moral yang baik cenderung menunjukkan perbedaan yang lebih kecil antara keputusan kebijakan/ teori yang dianut dan keputusan yang diambil/ teori yang sedang digunakan. 
Sampel dalam penelitian ini adalah manajer keuangan atau manajer akuntansi perusahaan manufaktur yang tergabung dalam PT SIER. Jumlah sampel dalam penelitian ini sebanyak 63 responden. Total kuesioner yang disebar adalah 78 kuesioner, akan tetapi yang kembali sebanyak 65 kuesioner, terdapat dua kuesioner yang tidak diisi dengan lengkap sehingga dikeluarkan dari pengujian.

Hipotesis dalam penelitian ini diuji menggunakan Structural Equation Modeling (SEM) dengan metode alternatif Partial Least Square (PLS) dengan menggunakan software WarpPLS 5.0. Hasil penelitian ini menunjukkan bahwa organizational ethical culture berpengaruh positif terhadap moral reasoning dan kecenderungan kecurangan akuntansi. Temuan berikutnya yaitu moral reasoning berpengaruh positif terhadap kecenderungan kecurangan akuntansi.

\section{LANDASAN TEORI DAN PENGEMBANGAN HIPOTESIS}

Victor dan Cullen (1988) mengonseptualisasikan organizational ethical culture sebagai persepsi karyawan tentang sejauh mana komitmen organisasi dalam kaitannya dengan masalah etika terhadap karyawan dan manajemennya. Marta (1999) menegaskan bahwa organizational ethical culture diciptakan dalam organisasi melalui praktik manajemen kebijakan etika, penegakan dan tindakan. Fang (2006), budaya etis organisasi menciptakan dan menanamkan keyakinan etis di antara anggotanya tentang apa yang dirasakan oleh anggota organisasi mereka akan meningkatkan kewajiban moral mereka untuk melindungi kepentingan organisasi yang mereka layani. Sebagai imbalannya, organisasi harus mendukung tindakan mulia anggota melalui penghargaan dan saluran pelaporan birokrasi yang lebih sedikit.

Organizational ethical culture menciptakan dan menanamkan keyakinan etis di antara anggota organisasi, lingkungan etis yang kuat dapat membantu mengurangi kecenderungan manajer untuk berperilaku oportunistik ketika terdapat masalah agensi (agency problems) (Booth \& Schulz, 2004). Menciptakan sebuah lingkungan etis yang kuat dapat menjadi pilihan pengendalian yang sangat diharapkan bagi organisasi secara umum (Akhyarudin dan Asnawi, 2017).

Moralitas adalah sifat moral atau keseluruhan asas dan nilai yang berkenaan dengan baik dan buruk (Bertens, 2002: 5). Moralitas dipahami sebagai suatu tata aturan yang mengatur tentang pengertian baik dan buruk perbuatan manusia sehingga manusia dapat membedakan bahwa perbuatan itu benar atau salah, baik atau buruk, boleh dilakukan atau bahkan dilarang sekalipun ia dapat mewujudkannya. Moralitas adalah suatu asas dan kaidah kesusilaan dalam hidup bermasyarakat.

Moralitas dapat dibedakan menjadi moralitas individu, moralitas sosial, dan moralitas mondial. Moralitas individu merupakan kesadaran tentang prinsip baik yang bersifat ke dalam, tertanam dalam diri manusia yang akan memengaruhi cara berpikir dan bertindak. Moralitas muncul dari dalam, bukan karena dipaksa dari luar. Moralitas merupakan sikap hati yang terungkap dalam perbuatan lahiriah. Moralitas sosial tecermin dari moralitas individu dalam melihat kenyataan sosial, yaitu cara individu melihat orang lain sebagai manusia yang memiliki harkat dan martabat yang sama. Sedangkan moralitas mondial adalah moralitas yang bersifat universal dan berlaku di mana pun dan kapan pun, terkait dengan keadilan, kemanusiaan, kemerdekaan dan sebagainya. 
Organizational Ethical Culture dengan Moral Reasoning dan Kecenderungan Kecurangan Akuntansi

Organizational ethical culture menciptakan dan menanamkan keyakinan etis di antara anggota organisasi, lingkungan etis yang kuat dapat membantu mengurangi kecenderungan manajer untuk berperilaku oportunistik ketika terdapat masalah agensi (agency problems) (Booth \& Schulz, 2004). Menciptakan sebuah lingkungan etis yang kuat dapat menjadi pilihan pengendalian yang sangat diharapkan bagi organisasi secara umum (Akhyarudin dan Asnawi, 2017). budaya organisasi yang etis akan meningkatkan moral seseorang sehingga seseorang tersebut dapat memilah-milah mana yang baik dan buruk. Selain itu, budaya organisasi yang etis akan mendorong seseorang untuk melakukan hal-hal terpuji dan menjauhi hal-hal yang buruk, salah satunya yaitu tindakan kecurangan. Oleh karena itu, hipotesis yang diajukan dalam penelitian ini adalah sebagai berikut.

H1: Organizational ethical culture berpengaruh negatif terhadap kecederungan kecurangan akuntansi.

H2: Organizational ethical culture berpengaruh positif terhadap moral reasoning.

\section{Moral Reasoning dengan Kecenderungan Kecu- rangan Akuntansi}

Moralitas adalah sifat moral atau keseluruhan asas dan nilai yang berkenaan dengan baik dan buruk (Bertens, 2002: 5). Moralitas dipahami sebagai suatu tata aturan yang mengatur tentang pengertian baik dan buruk perbuatan manusia sehingga manusia dapat membedakan bahwa perbuatan itu benar atau salah, baik atau buruk, boleh dilakukan atau bahkan dilarang sekalipun ia dapat mewujudkannya.
Moralitas adalah suatu asas dan kaidah kesusilaan dalam hidup bermasyarakat. moral reasoning adalah salah satu faktor yang sangat menentukan baik buruknya sikap seseorang (Near \& Miceli, 1995). Individu yang memiliki penalaran moral yang lebih tinggi memiliki kecenderungan untuk melakukan hal-hal terpuji dibandingkan dengan individu yang memiliki penalaran moral yang lebih rendah (Liyanarachchi \& Newdick, 2009). Individu dengan penalaran moral yang tinggi cenderung akan menjauhi sikap-sikap yang cenderung merugikan orang lain, berdasarkan hal tersebut, maka hipotesis yang diajukan dalam penelitian ini adalah sebagai berikut.

H3: moral reasoning berpengaruh negatif terhadap kecenderungan kecurangan akuntansi.

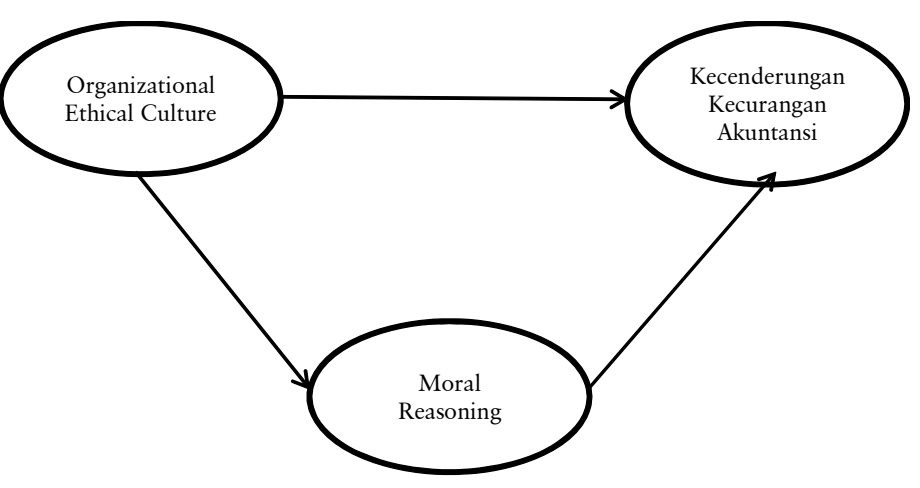

HASIL

Sampel dalam penelitian ini adalah manajer keuangan atau manajer akuntansi perusahaan manufaktur yang tergabung dalam PT SIER. Jumlah sampel dalam penelitian ini sebanyak 63 responden. Total kuesioner yang disebar adalah 78 kuesioner, akan tetapi yang kembali sebanyak 65 kuesioner, terdapat dua kuesioner yang tidak diisi dengan lengkap, sehingga dikeluarkan dari pengujian.

Hipotesis dalam penelitian ini diuji menggunakan structural equation modeling (SEM) 
dengan metode alternatif partial least square (PLS) dengan menggunakan software WarpPLS 5.0. Ada dua tahap dalam pengujian menggunakan SEM-PLS, yaitu analisis model pengukuran dan analisis model struktural. Tahap pertama yang dilakukan adalah mengevaluasi model pengukuran terlebih dahulu, setelah itu baru mengevaluasi model struktural. Proses perancangan model struktural dalam penelitian ini dengan menggunakan tiga konstruk (variabel laten). Konstruk tersebut terdiri dari satu konstruk eksogen dan dua konstruk endogen. Konstruk yang ada di dalam model struktural masing-masing memiliki indikator yang berfungsi sebagai alat ukur untuk indikator tersebut (Sholihin dan Ratmono, 2013).

Evaluasi model pengukuran bertujuan untuk mengetahui kualitas dari alat ukur (instrumen) dari sebuah konstruk. Terdapat dua pendekatan untuk mengukur konstruk dalam evaluasi model pengukuran, yaitu pengukuran reflektif dan pengukuran formatif. Penelitian ini hanya menggunakan satu pendekatan saja yaitu pendekatan pengukuran reflektif. Konstruk reflektif dinilai berdasarkan nilai cross loading masing-masing konstruk. Uji validitas dalam model pengukuran terdiri dari dua parameter, yaitu validitas konvergen dan validitas diskriminan.

\section{Uji Validitas dan Reliabilitas}

Uji validitas konvergen didasarkan pada faktor loading masing-masing indikator dari konstruk yang mana loading indikator lebih besar dari 0.70 , sedangkan untuk uji validitas diskriminan dinilai dengan cara membandingkan akar kuadrat dari average variance extracted (AVE) dengan korelasi antar konstruk, atau bisa juga dengan cara membandingkan loading konstruk yang diukur dengan loading konstruk yang lain- nya (Sholihin dan Ratmono, 2013). Pengujian reliabilitas diukur menggunakan composite reliability dan cronbach alpha. Rule of thumb dari composite reliability dan cronbach alpha adalah lebih besar dari 0,70 (Sholihin dan Ratmono, 2013).

Validitas konvergen berhubungan dengan prinsip bahwa pengukur-pengukur dari suatu konstruk seharusnya berkorelasi tinggi (Hartono dan Abdillah, 2014). Uji validitas konvergen dinilai berdasarkan pada faktor loading masingmasing konstruk lebih besar dari 0.70 (Sholihin dan Ratmono, 2013). Tabel 1 di bawah ini menyajikan hasil pengujian dari masing-masing konstruk.

Tabel 1.1 Nilai Loading Kombinasi dan Faktor Loading

\begin{tabular}{|c|c|c|c|}
\hline Variabel & Item & Loading & P-Value \\
\hline \multirow{5}{*}{$\begin{array}{l}\text { Organizational } \\
\text { Ethical Culture } \\
\text { (OEC) }\end{array}$} & OEC1 & 0,712 & $<0,001$ \\
\hline & $\mathrm{OEC} 2$ & 0,844 & $<0,001$ \\
\hline & OEC3 & 0,851 & $<0,001$ \\
\hline & OEC4 & 0,846 & $<0,001$ \\
\hline & OEC5 & 0,483 & $<0,001$ \\
\hline \multirow{6}{*}{$\begin{array}{l}\text { Moral Reasoning } \\
(\mathrm{MR})\end{array}$} & MR1 & 0,656 & $<0,001$ \\
\hline & MR2 & 0,724 & $<0,001$ \\
\hline & MR3 & 0,693 & $<0,001$ \\
\hline & MR4 & $-0,609$ & $<0,001$ \\
\hline & MR5 & $-0,685$ & $<0,001$ \\
\hline & MR6 & $-0,738$ & $<0,001$ \\
\hline \multirow{5}{*}{$\begin{array}{l}\text { Kecenderungan } \\
\text { Kecurangan } \\
\text { Akuntansi (KA) }\end{array}$} & KA1 & 0,755 & $<0,001$ \\
\hline & KA2 & 0,909 & $<0,001$ \\
\hline & KA3 & 0,810 & $<0,001$ \\
\hline & KA4 & 0,874 & $<0,001$ \\
\hline & KA5 & 0,876 & $<0,001$ \\
\hline
\end{tabular}

Tabel 1 menyajikan hasil uji validitas konvergen masing-masing konstruk. Hasil dari uji validitas konvergen tersebut menunjukkan ada beberapa indikator dari beberapa konstruk ada 
yang memiliki nilai faktor loading di bawah 0,07. Beberapa indikator tersebut yang dicetak tebal di dalam tabel tersebut. Untuk P-Value masing-masing indikator telah memenuhi kriteria, yaitu kurang dari 0,05. Indikator-indikator yang memiliki nilai faktor loading kurang dari 0,07 tidak dimasukkan dalam pengolahan data karena dianggap tidak memenuhi kriteria validitas konvergen.

Pengujian selanjutnya adalah uji validitas diskriminan. Uji validitas diskriminan dinilai dengan cara membandingkan akar kuadrat dari average variance extracted (AVE) dengan korelasi antar-konstruk atau bisa juga dengan cara membandingkan loading konstruk yang diukur dengan loading konstruk yang lainnya (Sholihin dan Ratmono, 2013).

Tabel 2 Korelasi antar-Variabel Laten

\begin{tabular}{|c|c|c|c|}
\hline & OEC & MR & KA \\
\hline OEC & $\mathbf{0 , 8 2 6}$ & 0,733 & 0,358 \\
\hline MR & 0,733 & $\mathbf{0 , 8 4 6}$ & 0,296 \\
\hline KA & 0,358 & 0,296 & $\mathbf{0 , 8 4 7}$ \\
\hline
\end{tabular}

Tabel 2 tersebut menyajikan hasil pengujian validitas diskriminan dari konstruk dalam penelitian ini. Hasil pada tabel di atas menunjukkan bahwa validitas diskriminan dalam penelitian ini telah terpenuhi dilihat dari nilai akar kuadrat dari AVE pada kolom diagonal lebih besar dari pada korelasi antar-konstruk pada kolom yang sama.

Pengujian selanjutnya Pengujian reliabilitas diukur menggunakan composite reliability dan cronbach alpha. Rule of thumb dari composite reliability dan cronbach's alpha adalah lebih besar dari 0,70 (Sholihin dan Ratmono, 2013). Hasil pengujian reliabilitas konsistensi internal dalam penelitian ini disajikan dalam Tabel 3 berikut ini.
Tabel 3 Hasil Uji Reliabilitas Konsistensi Internal

\begin{tabular}{|l|c|c|c|}
\hline \multicolumn{1}{|c|}{ Koefisien } & OEC & MR & KA \\
\hline Composite reliability & 0,895 & 0,883 & 0,926 \\
\hline Cronbach's alpha & 0,843 & 0,800 & 0,900 \\
\hline AVE & 0,683 & 0,717 & 0,717 \\
\hline
\end{tabular}

Pengujian selanjutnya adalah evaluasi model struktural. Evaluasi model struktural dalam SEM-PLS dengan menggunakan nilai koefisien determinasi $\left(\mathrm{R}^{2}\right)$ dan nilai Q-Squared. Berikut adalah hasil pengujian evaluasi model struktural yang tersaji dalam Tabel 4.

Tabel 4 Koefisien Variabel Laten

\begin{tabular}{|l|c|c|c|}
\hline \multicolumn{1}{|c|}{ Koefisien } & OEC & MR & KA \\
\hline $\mathrm{R}^{2}$ & & 0,618 & 0,177 \\
\hline$Q$-Squared & & 0,616 & 0,203 \\
\hline
\end{tabular}

Penelitian ini mengajukan tiga hipotesis (langsung) dan satu hipotesis (tidak langsung). Hipotesis dalam penelitian ini dikatakan terdukung apabila memiliki nilai $p$-value $<0,001$ (signifikan pada tingkat $1 \%$ ), p-value $<0,05$ (signifikan pada level 5\%) dan p-value $<0,1$ (signifikan pada level 10\%). berikut adalah hasil pengujian hipotesis dalam penelitian ini.

Tabel 5 Hasil Pengujian Hipotesis

\begin{tabular}{|c|c|c|l|}
\hline Hipotesis & P-value & $\begin{array}{c}\text { Path } \\
\text { Coefficients }\end{array}$ & Keterangan \\
\hline OEC $\rightarrow$ KKA (-) & 0,006 & 0,296 & Tidak Terdukung \\
\hline OEC $\rightarrow$ MR (+) & $<0,001$ & 0,786 & Terdukung \\
\hline $\mathrm{MR} \rightarrow$ KKA $(-)$ & 0,061 & 0,185 & Tidak terdukung \\
\hline
\end{tabular}

Berdasarkan Tabel 5 dapat dilihat bahwa H1 yaitu organizational ethical culture berpengaruh negatif terhadap kecenderungan kecurangan akuntansi tidak terdukung. Hal tersebut dapat dilihat dari koefisien jalur sebesar 0,296 (berarah positif) sehingga tidak sesuai dengan yang dihipotesiskan. Hasil pengujian hipotesis 1 di atas menunjukkan bahwa OEC berpengaruh positif terhadap KKA. Berlawanan dengan yang 
dihipotesiskan dalam penelitian ini. Hal tersebut terjadi karena moral individu yang bekerja di perusahaan-perusahaan tersebut sudah terbentuk dengan sangat kuat sehingga kondisi organisasi tidak dapat memengaruhinya, walaupun organisasi sangat mengedepankan budaya yang penuh etika tidak berpengaruh terhadap sikap para anggota organisasi tersebut.

Hipotesis kedua dalam penelitian ini yaitu organizational ethical culture berpengaruh positif terhadap moral reasoning terdukung. Hal tersebut dapat dilihat dari p-value sebesar $<0,001$ (signifikan pada level 1\%) dan path coefficient sebesar 0,786 (positif). Hasil tersebut menunjukkan bahwa kondisi organisasi yang menjunjung tinggi budaya beretika berpengaruh positif terhadap penalaran moral seseorang.

Hipotesis ketiga dalam penelitian ini yaitu moral reasoning berpengaruh negatif terhadap kecenderungan kecurangan akuntansi tidak terdukung. Walaupun $p$-value signifikan yaitu sebesar 0,06 (signifikan pada level 10\%) akan tetapi path coefficient bertolak belakang dengan yang dihipotesiskan, yaitu berarah positif. Hasil dari pengujian hipotesis ketiga ini adalah MR berpengaruh positif terhadap kecenderungan kecurangan akuntansi, yang artinya semakin tinggi penalaran moral seseorang maka semakin tinggi pula kecenderungan untuk melakukan tindakan kecurangan. Hal tersebut dapat terjadi karena adanya faktor-faktor lain, misalnya karena adanya impitan ekonomi, sehingga seseorang tersebut menganggap tindakan curang tersebut tidak melanggar norma karena sedang dalam kondisi terdesak.

\section{KESIMPULAN DAN SARAN}

Penelitian ini bertujuan untuk pengaruh organizational ethical culture terhadap moral reasoning dan kecenderungan kecurangan akuntansi. Berdasarkan pengujian hipotesis yang telah dilakukan, dapat disimpulkan bahwa organizational ethical culture berpengaruh positif terhadap moral reasoning dan kecenderungan kecurangan akuntansi. Temuan berikutnya yaitu moral reasoning berpengaruh positif terhadap kecenderungan kecurangan akuntansi.

Penelitian ini tidak lepas dari kekurangan, karena penelitian ini hanya dilakukan hanya pada satu sektor saja, yaitu perusahaan manufaktur. Untuk penelitian selanjutnya disarankan untuk meneliti semua sektor perusahaan, agar hasilnya dapat digeneralisasikan.

\section{DAFTAR PUSTAKA}

Ahyaruddin, M. \& Asnawi, M. 2017. "Pengaruh Moral Reasoning dan Ethical Environment Terhadap Kecenderungan untuk Melakukan Whistleblowing”. Jurnal Akuntansi \& Ekonomika, Vol. 1.

Booth, P. \& Schulz, A.K.-D. 2004. The Impact of an Ethical Environment on Managers' Project Evaluation Judgments Under Agency Problem Conditions. Accounting, Organizations and Society, 29(5-6), 473-488.

Cohen, J.R. \& Bennie, N.M. 2006. The Applicability of a Contingent Factors Model to Accounting Ethics Research. Journal of Business Ethics, 68(1), 1-18.

Craft, J. 2013. A Review of The Empirical Ethical Decision-Making Literature: 2004-2011. Journal of Business Ethics, 117 (2), 221-259.

Fang, M.L. 2006. Evaluating Ethical DecisionMaking of Individual Employees in Organizations - An Integration Framework. Journal of American Academy of Business, 8(2), 105-113. 
Fleischman, G.M., Valentine, S., \& Finn, D.W. 2007. Ethical Reasoning and Equitable Relief. Behavioral Research in Accounting, 19, 107-132.

Harrington, S.J. 1997. A Test of a Person-Issue Contingent Model of Ethical Decision Making in Organizations. Journal of Business Ethics, 16, 363-375.

Hartono, J. \& Abdillah, W. 2014. Konsep and Aplikasi PLS (Partial Least Square) untuk Penelitian Empiris, Edisi pertama. Yogyakarta: BPFE.

Hwang, D.B.K, Staley, A.B., Tsai, Y., \& Chui, C.L. 2013. A Comparative Study of the Propensity of Whistle-Blowing Empirical Evidence from China, Taiwan and the United States. International Journal of Accounting and Financial Reporting, 3 (2), 202-204.

Jones, T. 1991. Ethical Decision Making by Individuals in Organizations: An IssueContingent Model. Academy of Management Review, 16(2), 366-395.

Keenan, J.P. 1990. Upper-Level Managers and Whistleblowing: Determinants of Perceptions of Company Encouragement and Information About Where to Blow the Whistle. Journal of Business and Psychology, 5 (2), 223-235.

Keenan, J.P. 2000. Blowing the Whistle on Less Serious Forms of Fraud: A Study of Executives and Managers. Employee Responsibilities and Rights Journal, 12 (4), 199217.

Kreshastuti, D.K. dan Prastiwi, A. 2014. Analisis Faktor-Faktor yang Memengaruhi Intensi Auditor untuk Melakukan Tindakan Whistleblowing (Studi Empiris pada Kantor Akuntan Publik di Semarang). Diponegoro Journal of Accounting, Vol. 3, No. 2, pp. 2-8.
Liyanarachchi, G. \& Newdick, C. 2009. The Impact of Moral intensity and Retaliation on Whistle-Blowing: New Zealand Evidence. Journal of Business Ethics, 89(1), $37-57$.

Marta, J.K.M. 1999. An Empirical Investigation into Significant Factors of Moral Intensity and Their Influences on Ethical Judgments and Intentions. Doctoral Dissertation, Old Dominion University. (UMI No: 9928703). Retrieved May, 24, 2006 from http://www.proquest.umi.com.html/

May, D.R. \& Pauli, K.P. 2002. The Role of Moral Intensity in Ethical Decision Making. Business \& Society, 41(1), 84-117.

McLain, D.A., \& Keenan, J.P. 1999. Risk, Information, and the Decision About Response to Wrongdoing in an Organization. Journal of Business Ethics, 19, 255271.

Mendonca, M. 2001. Preparing for Ethical Leadership in Organizations. Canadian Journal of Administrative Science, 18 (5), 266276.

Near, J.P. \& Miceli, M.P. 1985. Organizational Dissidence: the Case of Whistle-Blowing. Journal of Business Ethics, 4(1), 1-16.

O'Fallon, M.J. \& Butterfield, K.D. 2005. A Review of the Empirical Ethical Decision Making Literature: 1996-2003. Journal of Business Ethics, 59, 375-413.

Rocha, E. \& Kleiner, B.H. 2005. To Blow or Not to Blow the Whistle? That is The Question. Management Research News, 28(11/12), 80-87.

Rothwell, G.R. \& Baldwin, J.N. 2007. Ethical Climate Theory, Whistle-Blowing, and the Code of Silence in Police Agencies in the State of Georgia. Journal of Business Ethics, 70(4), 341-361. 
Shawver, T. 2011. The Effects of Moral Intensity on Whistleblowing Behaviors of Accounting Professionals. Journal of Forensic and Investigative Accounting, 3(2), 162190.

Sholihin, M. and Ratmono, D. 2013. Analisis SEM-PLS dengan WarpPLS 3.0. Yogyakarta: CV Andi Offset.

Susmanschi, G. 2012. Internal Audit and Whistle-Blowing. Economics, Management, and Financial Markets, 7(4), 415-421.

Tjahjono, S. 2013. Business Crimes and Ethics: Konsep dan Studi Kasus Fraud di Indonesia dan Global. Yogyakarta: ANDI.
Trevino, L.K. 1986. Ethical Decision Making in Organizations: A Person-Situation Interactionist Model. Academy of Management Review, 11, 601-617.

Victor, B. \& Cullen, J.B., 1988. The Organizational Bases of Ethical Work Climate. Administrative Science Quarterly, 33 (5), 101-125.

Zakaria, M. 2015. Antecedent Factors of Whistleblowing in Organizations. Procedia Economics and Finance, Vol. 28, No. 1, pp. 230-234. 